\title{
Two-Dimensional 8/9 Error Correcting Modulation Code
}

\author{
Kyoungoh Lee*, Byungsun Kim, Jaejin Lee
}

\begin{abstract}
In holographic data storage (HDS), a high transmission rate is accomplished through the use of a charge coupled device array for reading two-dimensional (2D) pixel image data. Although HDS has many advantages in terms of storage capacity and data transmission rates, it also features problems, such as 2D intersymbol interference (ISI) by neighboring pixels and interpage interference (IPI) by multiple images stored in the same holographic volume. Modulation codes can be used to remove these problems. We introduce a 2D 8/9 error-correcting modulation code. The proposed modulation code exploits the trellis-coded modulation scheme, and the code rate is larger (about 0.889) than that of the conventional 6/8 balanced modulation code (an increase of approximately 13.9\%). The performance of the bit error rate (BER) with the proposed scheme was improved compared with that of the $6 / 8$ balanced modulation code and the simple $8 / 9$ code without the trellis scheme.
\end{abstract}

Key Words : Holographic data storage, Two-dimensional intersymbol interference, Modulation code

\section{I . Introduction}

Demands for increased storage capacity and fast access time will increase in the future. Holographic data storage (HDS) systems record information throughout the volume of the HDS media ${ }^{[1-3]}$. Furthermore, with HDS, the principle of writing and reading is different from other data storages, such as HDD, CD, DVD, and BD. HDS is a two-dimensional (2D) read/write system while other data storages are one-dimensional. HDS contributes a high storage capacity and transfer rate to holographic data storage systems. Although HDS has these two strengths, it also has some weaknesses that need to be addressed and solved, such as intersymbol interference (ISI), interpage interference (IPI), and misalignment ${ }^{[4,5]}$.

In particular, HDS is characterized by two-dimensional (2D) ISI, since the reading by a charge-coupled device causes the data pages to blur, which degrades the bit error rate (BER) performance.
To mitigate the 2D ISI problem, many researchers have conducted studies on 2D modulation $\operatorname{codes}^{[5-11]}$. One scheme is to remove the source of the 2D ISI, such as the isolated ON or OFF pixel patterns ${ }^{[5,6]}$. The modulation code prohibits the patterns of high spatial frequency. A series of factors, such as the finite extent of the medium, the shape of the beams, the imperfections in the optics, and the use of a phase mask, tend to truncate or distort high spatial frequencies in the HDS system ${ }^{[5]}$. Another scheme is to furnish the modulation codes with an error correcting capability ${ }^{[8-11]}$. Pansatiankul and Sawchuk presented 3D interleaved error correcting schemes based on Reed-Solomon $\operatorname{codes}^{[8]}$. Burr et al. proposed an 8:12 code to enhance robustness against noise because the minimum Hamming distance between the codewords is larger ${ }^{[9]}$. Kim and Lee introduced an error correcting modulation scheme exploiting a trellis modulation structure ${ }^{[11]}$. They collected codewords with a minimum Hamming distance greater than or equal to 2 and appropriately

※ 이 논문은 2013년도 정부(교육부)의 재원으로 한국연구재단의 지원을 받아 수행된 기초연구사업임(NRF-2013R1A1A2059077).

- First Author : Information and Telecommunications Lab., Soongsil University, kasinamooth@naver.com, 학생회원

- Corresponding Author: Information and Telecommunications Lab., Soongsil University, zlee@ssu.ac.kr, 종신회원 논문번호 : KICS2014-02-060, Received February 17, 2014; Reviewed February 24, 2014; Accepted February 24, 2014 
assigned the codewords to each branch in order to insure that the distance of the shortest error event was as large as possible. The encoding procedure starts from setting the initial state as $\mathrm{S}_{0}$. For each input block, the encoder outputs a codeword corresponding to the input and moves to the next state. This is repeated $\mathrm{m}$ times. Then, a parity symbol is inserted for going back to the state $S_{0}$. The procedure is repeated to the end of the input data.

In order to exceed the previous work ${ }^{[9-11]}$, this paper focused on a high code rate error correcting modulation code for high density HDS. Therefore, we propose an error correcting 8/9 modulation code, which reinforces the data storage capacity advantage of HDS.

In Section 2, we introduce a 2D 8/9 modulation code with the minimum Hamming distance of 2 and explain the trellis modulation scheme that is used for its error correcting capability. Section 3 discusses the simulation results comparing the proposed code and the conventional 6/8 balanced modulation code, which has an equal number of $\mathrm{ON}$ and OFF pixels. Finally, we present our conclusions in Section 4.

\section{8/9 Error-Correcting Modulation Code}

The 2D 8/9 modulation code has 256 codewords and is composed of a $3 \times 3$ nine pixel array. We selected 256 symbols having an odd number of ON pixel patterns, such as 9 symbols of one ON pixel (Type 1), 84 symbols of three ON pixels (Type 3), 126 symbols of five ON pixels (Type 5), 36 symbols of seven ON pixels (Type 7), and 1 symbol of nine ON pixels (Type 9), as shown in Fig. 1. The 8/9 modulation code has a minimum Hamming distance equal to 2 .

The encoder used for the no error correcting $8 / 9$ modulation code (referred to as the No ECC $8 / 9$ code) is a simple one-to-one mapping. The code rate of the No ECC $8 / 9$ code is 0.889 , which is larger than the code rate of the $6 / 8$ balanced modulation codes.

Modulation codes that use a trellis structure can

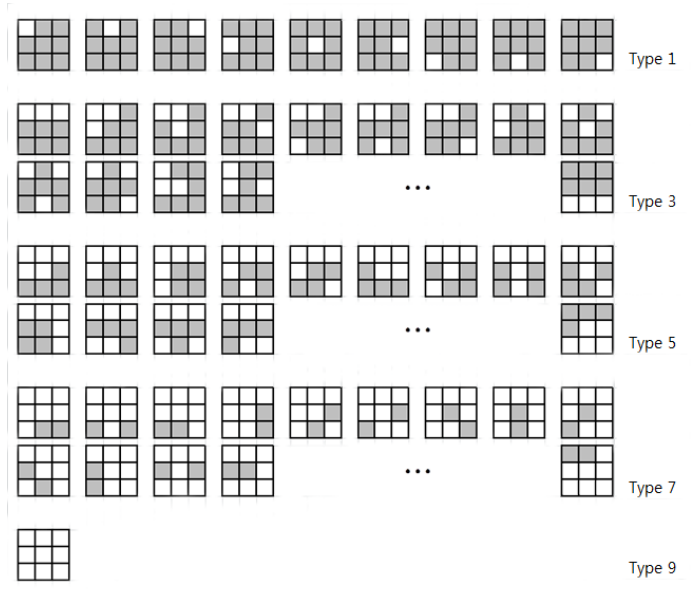

Fig. 1. Set of 256 symbols

correct error problems. Since the No ECC 8/9 code has a minimum Hamming distance equal to 2 , an error correcting 8/9 modulation coding scheme can be done by exploiting the trellis modulation scheme that has the shortest error event distance greater than 3. This structure has 256 states because the input is an 8-bit input. Table 1 shows the encoding rule. This method has a terminating parity symbol. This parity symbol makes the trellis go back to $S_{0}$ for coding gain. Therefore, the true code rate becomes $8 \mathrm{~m} / 9(\mathrm{~m}+1)$, where $\mathrm{m}$ is the interval between the terminating parity symbols. The encoding procedure is as follows. At first, we set the initial state as $S_{0}$. Then, for each 8-bit input, the encoder outputs a symbol corresponding to the input and moves to the next state. This is repeated $\mathrm{m}$ times. Then, a parity symbol is inserted for going back to the state $S_{0}$. These procedures are repeated while the input data remain. An example of the encoding procedure is shown in Fig. 2.

\section{Simulation}

\subsection{Experimental environment}

To evaluate each modulation code's performance, we simulated data pages with a $1024 \times 1024$ array size for each page. The grade of blur is 1.85 , and the channel noise is additive white Gaussian noise (AWGN). We defined the channel signal-to-noise ratio (SNR) as the AWGN power. There are 
Table 1. Coding table of modulation method (256 states)

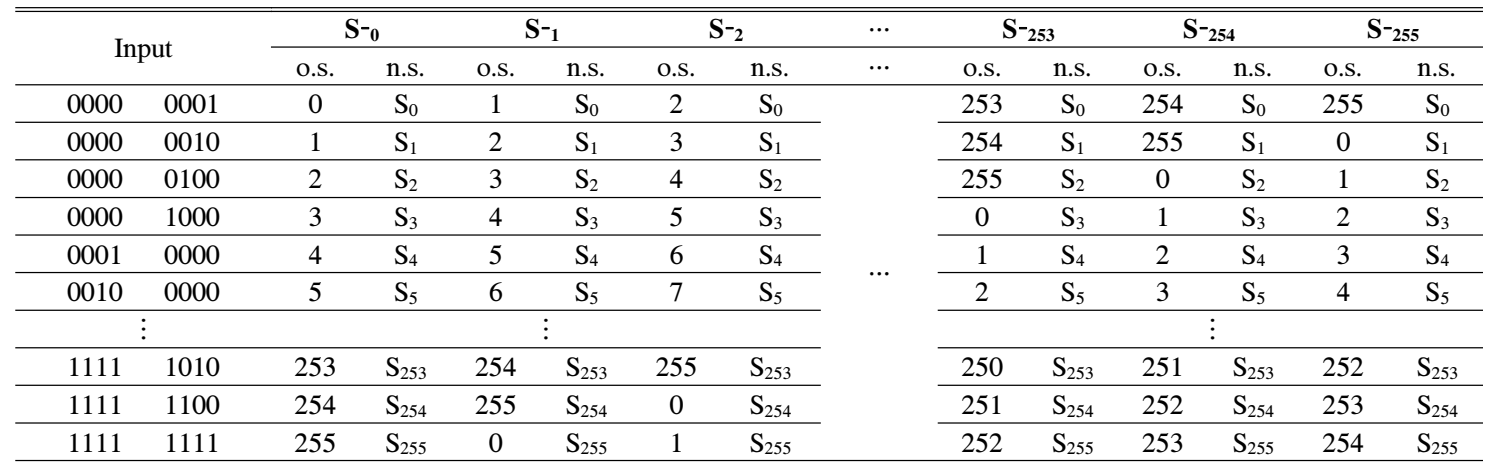

o.s. : output symbol, n.s. : next state

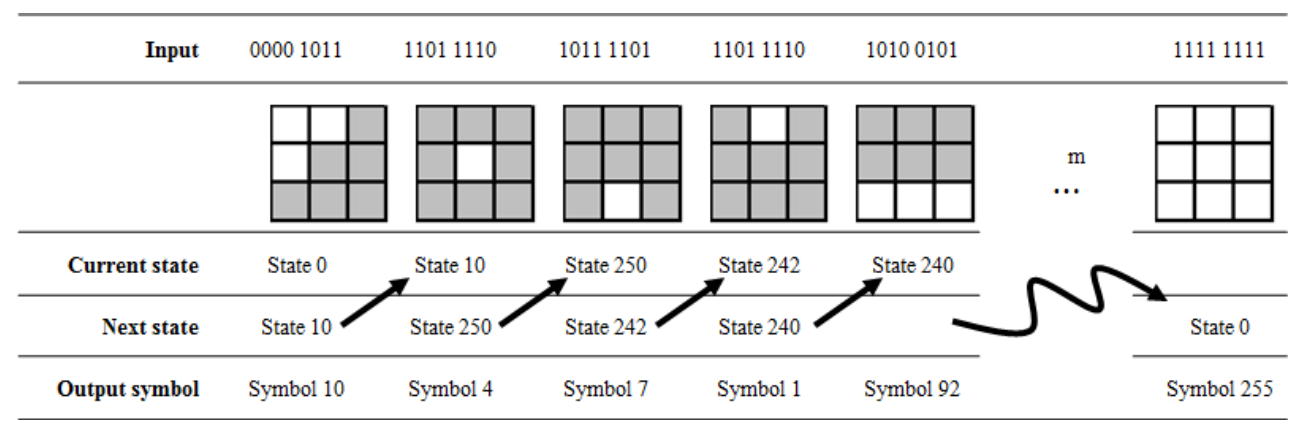

Fig. 2. An example of encoding procedure of the proposed error-correcting modulation

horizontal and vertical axis misalignments (10\%, $10 \%)$. The detection process is a $2 \mathrm{D}$ soft-output Viterbi algorithm (SOVA) ${ }^{[12]}$. We choose the interval between the terminating parity symbols to be $30(\mathrm{~m}=30)$.

\subsection{Simulation results}

Figure 3 shows the performance depending on the grade of the blur when the SNR is $15 \mathrm{~dB}$. The ECC $8 / 9$ code performs best below the blur of 1.95 . However, as the grade of blur increases, which means a bad channel condition, the performance of the No ECC 8/9 code and the balanced $6 / 8$ modulation code are better than the performance of the ECC $8 / 9$ code. If the channel condition is favorable, the performance of the trellis scheme can be improved. The performance of the No ECC 8/9 code is better than the performance of the balanced $6 / 8$ code because the decoder of the No ECC 8/9 code uses 9 pixels to decode information.

The BER performance with AWGN is shown in
Figure 4. The No ECC $8 / 9$ code shows the best BER performance below $11 \mathrm{~dB}$. On the other hand, as the SNR increases, the proposed ECC 8/9 code performs better than both the $6 / 8$ balanced code and the No ECC $8 / 9$ code. The ECC $8 / 9$ coding and the No ECC $8 / 9$ code correct all the error bits at $15 \mathrm{~dB}$ and $17 \mathrm{~dB}$, respectively.

Figure 5 illustrates the BER performance according to horizontal and vertical misalignment. In the simulation, the $\mathrm{SNR}$ is $15 \mathrm{~dB}$, and the grade of blur is 1.85 . Overall, the performance of the No ECC $8 / 9$ code is better than the performance of the $6 / 8$ balanced code. The BER performance of the ECC $8 / 9$ code is decreased as the misalignment increases because the trellis scheme is unable to function when the channel condition is poor.

Figure 6 shows the BER performance depending on the interval between the parity symbols. However, the ECC 8/9 modulation code shows variation according to the interval between the 


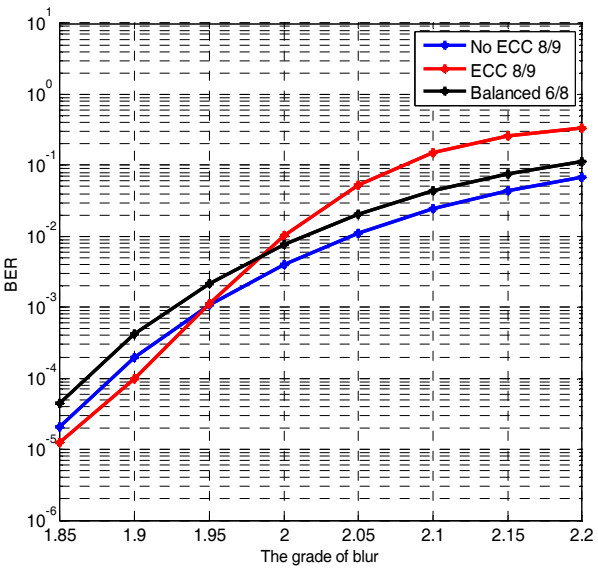

Fig. 3. BER performance in accordance with blur



Fig. 5. BER performance according to misalignments.

terminating parity symbols. There is a trade-off between the BER and the code rate, which means that a better BER requires a lower code rate.

\section{Conclusion}

We proposed a two-dimensional 8/9 modulation code for Holographic data storage (HDS). This modulation code increases the data transmission rate compared to the balanced 6/8 modulation code (by approximately $13.9 \%$ ). Since the proposed code has a minimum Hamming distance of 2, we can apply the trellis modulation scheme for its error correcting capability. While the channel condition is not vulnerable, the proposed $8 / 9$ code with trellis



Fig. 4. Comparison of BER performance with AWGN

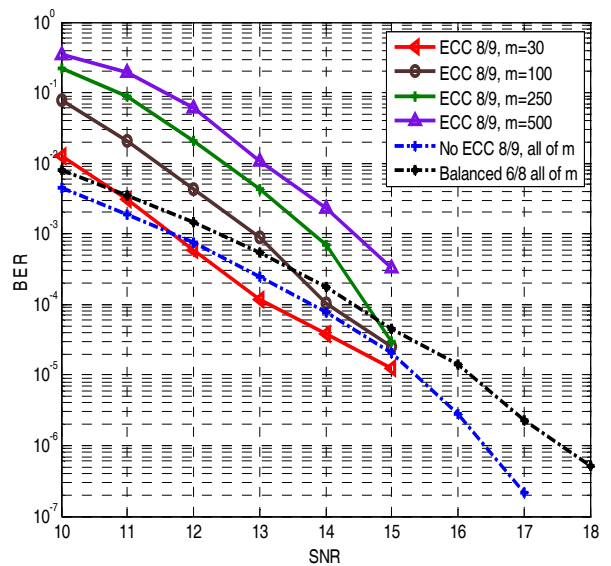

Fig. 6. BER performance according to the interval between parity symbols $(\mathrm{m})$.

modulation shows better BER performance than the $6 / 8$ balanced modulation code.

Table 2. Value of at $15 \mathrm{~dB}$ point

\begin{tabular}{c|c|c}
\hline Modulation code & interval $(\mathrm{m})$ & BER \\
\hline \multirow{2}{*}{$\begin{array}{c}\text { Error-correcting } \\
8 / 9 \text { modulation }\end{array}$} & 30 & 0.000012677372 \\
\cline { 2 - 3 } & 250 & 0.000030220350 \\
\cline { 2 - 3 } & 500 & 0.000334772381 \\
\hline $\begin{array}{c}\text { No ecc 8/9 } \\
\text { modulation }\end{array}$ & All & 0.000020639657 \\
\hline $\begin{array}{c}\text { Balanced 6/8 } \\
\text { modulation }\end{array}$ & All & 0.000044759115 \\
\hline
\end{tabular}




\section{References}

[1] R. M. Shelby, J. A. Hoffnagle, G. W. Burr, C. M. Jefferson, M.-P. Bernal, H. Coufal, R. K. Grygier, H. Gunter, R. M. Macfalane, and G. T. Sincerbox, "Pixel matched holographic data storage with megabit pages," Opt. Lett., vol. 22, no. 19, pp. 1509-1511, 1997.

[2] W. Liu and D. Psaltis, "Pixel size limit in holographic memories," Opt. Lett., vol. 24, no. 19, pp. 1340-1342, 1999.

[3] L. Hesselink, S. S. Orlov, and M. C. Bashaw, "Holographic data storage systems," in Proc. IEEE, vol. 92, no. 8, pp. 1231-1280, 2004.

[4] V. Vadde and B. V. K. V. Kumar, "Channel modeling and estimation for intrapage equalization in pixel-matched volume holographic data storage," Appl. Opt., vol. 38, no. 20, pp. 4374-4386, 1999.

[5] J. J. Ashley and B. H. Marcus, "Twodimensional low-pass filtering codes," IEEE Trans. Commun., vol. 46, no. 6, Jun. 1998.

[6] N. Kim, J. Lee, and J. Lee, "Rate 5/9 two-dimensional pseudo balanced code for holographic data storage systems," Jpn. J. Appl. Phys., vol. 45, no. 2B, pp. 1293-1296, Feb. 2006.

[7] D. Park, M. Yoo, and J. Lee, "Tonecontrollable codes for holographic data storage," Jpn. J. Appl. Phys., vol. 49, no. 8, pp. 08KB05, Aug. 2010.

[8] D. E. pansatiankul and A. A. Sawchuk, "Multi-dimensional modulation codes and error correction for page-oriented optical data storage," in Proc. SPIE, vol. 4342, pp. 393-400, Jan. 2002.

[9] G. W. Burr, J. Ashley, H. Coufal, O. K. Greygier, J. A. Hoffnagle, C. M. Jefferson, and B. Marcus, "Modulation coding for pixel-matched holographic data storage," Opt. Lett., vol. 22, no. 9, pp. 639-641, 1997.

[10] G. Yang, J. Kim, and J. Lee, "Mis- alignment channel performance of error correcting $4 / 6$ modulation codes for holographic data storage," J. KICS, vol. 35 , no. 12, pp.
971-976, Dec. 2010.

[11] J. Kim and J. Lee, "Error-correcting 6/8 modulation code for reducing two-dimensional intersymbol interference," Jpn. J. Appl. Phys., vol. 50, no. 9, pp. 09MB06, Sept. 2011.

[12] J. Kim and J. Lee, "Two-Dimensional SOVA and LDPC codes for holographic data storage system," IEEE Trans. Magn., vol. 45, no. 5, pp. 2260-2263, May 2009.

이 경 오 (Kyungoh Lee)

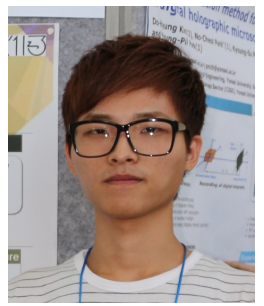

2008년 3월 : 숭실대학교 정보 통신전자공학부 학사 입학 2014년 2월 : 숭실대학교 정보 통신전자공학부 학사 졸업 <관심분야> 스토리지 시스템

김 병 선 (Byungsun Kim)



이 재 진 (Jaejin Lee)

(2014년 2월호 참조) 